\title{
Self-Association-Free and Recyclable, Dimeric Cinchona Alkaloid Organocatalysts for Methanolytic Desymmetrization of meso-Glutaric Anhydrides ${ }^{\dagger}$
}

\author{
Eun Hye Nam, Sang Eun Park, Joong Suk Oh, Surajit Some, Dae Young Kim, Han Yong Bae, and Choong Eui Song* \\ Department of Chemistry, Department of Energy Science, Sungkyunkwan University 300 Cheoncheon, \\ Jangan, Suwon, Gyeonggi 440-746, Korea. ${ }^{*}$-mail: s1673@skku.edu \\ Received March 7, 2011, Accepted March 11, 2011
}

Key Words : Asymmetric organocatalysis, Bifunctional catalysis, Desymmetrization of meso-glutaric anhydrides, Squaramide-based dimeric cinchona alkaloid catalysts, Catalyst self-association

There has been considerable interest in the stereoselective ring opening of meso-cyclic anhydrides, since the resulting hemiesters are used as versatile intermediates in the construction of many bioactive compounds. ${ }^{1}$ Especially, the chiral 3substituted glutaric acid monoesters 2 produced by the alcoholysis of meso-glutaric anhydrides 1 (Scheme 1) are used as key intermediates for the synthesis of a variety of industrially interesting pharmaceutical compounds, e.g., $\gamma$ aminobutyric acid (GABA) analogs, ${ }^{2}$ selective serotonin receptor antagonists (e.g., Paroxetin $\cdot \mathrm{HCl})^{3}$ and potent $\mathrm{P} 2 \mathrm{X} 7$ receptor antagonists, ${ }^{4}$ etc. Much effort has, therefore, been made to develop efficient enzymatic and non-enzymatic catalytic systems for the alcoholysis of the meso-glutaric anhydrides 1. ${ }^{1}$ However, the results obtained with meso-glutaric anhydrides as substrates are still unsatisfactory for practical use, whereas alcoholysis with other types of meso-anhydrides, such as bi-, tricyclic and succinic anhydrides, usually gives excellent results. All of the approaches involving the use of meso-glutaric anhydrides as substrates suffer from either a narrow substrate scope and/or very long reaction time and unsatisfactory enantioselectivity. Even enzymatic processes gave very low enantioselectivities. ${ }^{5}$

Recently, we and another research group employed bifunctional (thio) ureas as organic chiral catalysts for the alcoholytic desymmetrization of meso-glutaric anhydrides. ${ }^{6,7}$ However, their enantioselectivity ( $\sim 80 \%$ ee) are still unsatisfactory for the synthetic use. Moreover, with this type of catalysts, high ees can be obtained only under conditions of extremely high dilution. We identified the reason for this unusual concentration-dependence in terms of the self-association of the catalyst. ${ }^{6}$ When considering the reaction time, volume yield, etc., this type of catalysts is highly undesirable for practical use. Thus, it would be highly desirable to develop a new class of highly enantioselective and self-association free organocatalysts for the alcoholytic desymmetrization of meso-glutaric anhydrides $\mathbf{I}$.

We have recently developed novel self-association free chiral bis-squaramide catalysts $\mathbf{3}$, in which the steric bulk of the two alkaloid moieties suppress their self-aggregation. ${ }^{8}$

${ }^{\top}$ This paper is dedicated to Professor Eun Lee on the occasion of his honourable retirement.
Now we report on their use as highly enantioselective catalysts for the alcoholytic desymmetrization of meso-glutaric anhydrides 1. Detailed experimental studies and diffusion ordered spectroscopy (DOSY) data revealed that this type of bifunctional organocatalysts do not self aggregate to any appreciable extent in solution.

To examine the catalytic activity and enantioselectivity of $\mathbf{3}$ we first conducted desymmetrization of 3-OTBDPS glutaric anhydride 1a in presence of the catalysts $(10 \mathrm{~mol} \%)$ and $\mathrm{MeOH}$ (10 equiv) in THF. The results are depicted in Table 1 , with the data obtained using the monomeric thiourea and

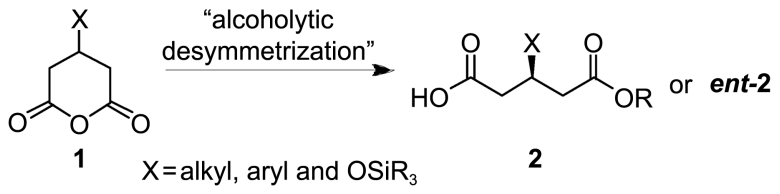

Scheme 1

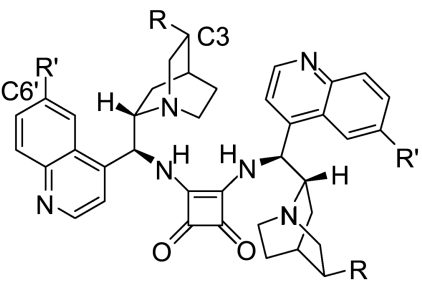

3a, Bis-QN-SQA: $R=$ vinyl, $R^{\prime}=O M e$ 3b, Bis-HQN-SQA: R= ethyl, R' = OMe 3c, Bis-CD-SQA: $R=$ vinyl, $R^{\prime}=H$ 3d, Bis-HCD-SQA: $R=$ ethyl, $R^{\prime}=H$<smiles>[R]C1CN2CCC1N2[C](NC(=S)Nc1cc(C(F)(F)F)cc(C(F)(F)F)c1)c1ccnc2ccc(OC)cc12</smiles>

4a, QN-TU: $R=$ vinyl 4b, HQN-TU: R=ethyl<smiles>[R]C1CC2CCN1CC2[C@H](Nc1c(NCc2cc(C(F)(F)F)cc(C(F)(F)F)c2)c(=O)c1=O)c1ccnc2ccc(OC)cc12</smiles>

5a, QN-SQA: R=vinyl 5b, HQN-SQA: $R=$ ethyl

Figure 1. Cinchona-based organocatalysts tested in our study (QN $=$ quinine; $\mathrm{HQN}=$ hydroquinine; $\mathrm{CD}=$ cinchonidine; $\mathrm{HCD}=$ hydrocinchonidine). 
squaramide catalyst, $\mathbf{4}$ and $\mathbf{5}$, respectively. As shown in Table 1 , regardless of the substituent at the $\mathrm{C} 3$ and C6' positions of alkaloids 3a-d, the methanolysis of $\mathbf{1 a}$ proceeded smoothly, affording the corresponding hemiester $\mathbf{2 a}$ in excellent yields and ee values (90-91\% ee) (Table 1, entries 5-8). Moreover, enantioselectivities of dimeric squaramide catalysts 3 are slightly higher compared with those of other type of catalysts $\mathbf{4}$ and $\mathbf{5}$ (Table 1, entries 1-4).

More interestingly, as depicted in Figure 2, the enantioselectivity of the squaramide-based (square symbols) dimeric catalyst Bis-HQN-SQA (3b) was not significantly dependent on the concentration. In contrast to these results, using other type of monomeric catalysts QN-TU (4a) and HQN-SQA (5a), the enantioselectivity decreases significantly on increasing the concentration. On the basis of these experimental

Table 1. Catalytic enantioselective ring opening of $1 a$ with $\mathrm{MeOH}$ in presence of different catalysts ${ }^{a}$

\begin{tabular}{clccc} 
Entry & \multicolumn{3}{c}{ Catalyst } & Time (h) \\
\hline 1 & QN-TU (4a) & 4.5 & 96 & 83 \\
2 & HQN-TU (4b) & 5.5 & 83 & 83 \\
3 & QN-SQA (5a) & 3 & 96 & 86 \\
4 & HQN-SQA (5b) & 3 & 94 & 87 \\
5 & Bis-QN-SQA (3a) & 5 & 92 & 90 \\
6 & Bis-HQN-SQA (3b) & 5 & 94 & 90 \\
7 & Bis-CD-SQA (3c) & 5 & 93 & 91 \\
8 & Bis-HCD-SQA (3d) & 5 & 94 & 90 \\
\hline
\end{tabular}

${ }^{a}$ Reactions were carried out with $\mathbf{1 a}(0.5 \mathrm{mmol}), 10$ equiv. of $\mathrm{MeOH}$ and catalysts $(10 \mathrm{~mol} \%)$, in THF $(10 \mathrm{~mL})$ at ${ }^{\mathrm{rt}}{ }^{b}$ Isolated yields after chromatographic purification. ${ }^{c}$ Determined by chiral HPLC (see Supporting Information).
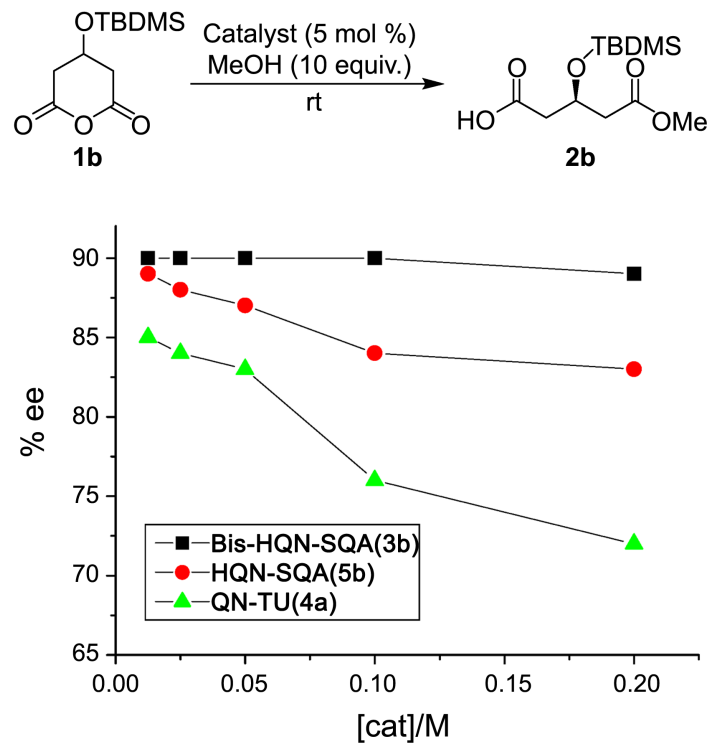

Figure 2. Effect of concentration on the enantioselectivity in the methanolytic desymmetrization of $\mathbf{1 b}$.
Table 2. Enantioselective methanolysis of various meso-glutaric anhydrides

\begin{tabular}{|c|c|c|c|c|c|}
\hline & $\begin{array}{r}\text { Bis-HC } \\
(1 \\
\mathrm{MeO}\end{array}$ & $\begin{array}{l}\text { N-SQA (3b) } \\
\text { mol \%) } \\
\text { (10 equiv) } \\
\text { THF }\end{array}$ & \multicolumn{2}{|r|}{$2 a-f$} & \\
\hline Entry & $\mathrm{X}$ & Temp $\left({ }^{\circ} \mathrm{C}\right)$ & $\mathrm{T}(\mathrm{h})$ & Yield (\%) & ee $(\%)^{c}$ \\
\hline 1 & OTBDPS (1a) & $\mathrm{rt}$ & 5 & 92 & 91 \\
\hline 2 & OTBDMS (1b) & $\mathrm{rt}$ & 4 & 91 & 90 \\
\hline 3 & 4-Ph (1c) & -20 & 46 & 92 & 89 \\
\hline 4 & 4-F-Ph (1d) & -20 & 48 & 98 & 89 \\
\hline 5 & 4-OMe-Ph (1e) & -20 & 48 & 98 & 93 \\
\hline 6 & 4-Cl-Ph (1f) & -20 & 48 & 98 & 90 \\
\hline
\end{tabular}

${ }^{a}$ Reactions were carried out with 1a-f $(0.5 \mathrm{mmol}), 10$ equiv of $\mathrm{MeOH}$ and catalysts $\mathbf{3 b}(10 \mathrm{~mol} \%)$ in THF $(10 \mathrm{~mL})$ at $20{ }^{\circ} \mathrm{C}$ or $-20{ }^{\circ} \mathrm{C}$. ${ }^{b}$ Isolated yields after chromatographic purification. ${ }^{\circ}$ Determined by chiral HPLC. ${ }^{6,10}$

results, it is clear that the self-association phenomenon is not as significant in the methanolysis of glutaric anhydrides with the bifunctional dimeric catalyst $\mathbf{3}$ as it is in the process catalyzed by 4 or 5 .

Moreover, a DOSY study, which is regarded as an invaluable tool for studying self-association phenomena in solution, also showed the self-association free nature of dimeric catalysts. Whereas the diffusion coefficients $\left(D\left[10^{-10} \mathrm{~m}^{2} \mathrm{~s}^{-1}\right]\right)$ of the monomeric catalysts, QN-TU (4a) and HQN-SQA (5b), significantly decreased on increasing the concentration from $10 \mathrm{mM}$ to $20 \mathrm{mM}$ (for $4 \mathrm{a}$ : from $5.47 \times 10^{-10} \mathrm{~m}^{2} \mathrm{~s}^{-1}$ to $4.52 \times 10^{-10} \mathrm{~m}^{2} \mathrm{~s}^{-1}$; for $\mathbf{5 b}$ : from $4.33 \times 10^{-10} \mathrm{~m}^{2} \mathrm{~s}^{-1}$ to $3.50 \times$ $10^{-10} \mathrm{~m}^{2} \mathrm{~s}^{-1}$ ), those of the dimeric catalyst, Bis-HQN-SQA (3b), did not show any appreciable dependence on the concentration (from $5.12 \times 10^{-10} \mathrm{~m}^{2} \mathrm{~s}^{-1}$ to $5.08 \times 10^{-10} \mathrm{~m}^{2} \mathrm{~s}^{-1}, \Delta D=$ $\left.-0.04 \times 10^{-10} \mathrm{~m}^{2} \mathrm{~s}^{-1}\right)$, in contrast to the monomeric catalyst. ${ }^{8,9}$

Having established that the dimeric squaramide catalysts 3 act as highly enantioselective and self-association free catalysts, we undertook to explore the scope of the substrate under the optimized reaction conditions. As shown in Table 2 , a variety of meso-glutaric anhydrides 1a-f, regardless of their substitution patterns at the 3-position of 1 (3-aryl and 3silyl protected hydroxyl groups), were smoothly converted into the corresponding hemiester products 2a-f with high enantioselectivity. Furthermore, due to their robust nature, the dimeric squaramide catalysts $\mathbf{3}$ could be easily recovered $(>95 \%)$ from the reaction mixture after extractive acid/base work up, allowing their repeated recycling without any loss of turnover time or enantioselectivity.

\section{Conclusions}

Highly enantioselective methanolytic desymmetrization of meso-glutaric anhydrides has been achieved using the dimeric squaramide catalysts $\mathbf{3}$ which could be easily recovered $(>96 \%)$ from the reaction mixture after extractive acid/base work up, allowing their repeated recycling without any loss of turnover time or enantioselectivity. Detailed experimental studies and diffusion ordered spectroscopy (DOSY) data 
revealed that these bifunctional organocatalysts that do not self aggregate to any appreciable extent in solution.

\section{Experimental Section}

\section{General Procedure for Methanolytic Desymmetrization} of meso-Glutaric Anhydrides: $\mathrm{MeOH}$ (5 mmol) was added to a stirred solution of the meso-anhydrides $(0.5 \mathrm{mmol})$ and catalyst $3(10 \mathrm{~mol} \%)$ in THF $(10 \mathrm{~mL}, 0.05 \mathrm{M})$ at the temperature indicated in Table 1-2 and Figure 3. The reaction was stirred until the starting material was consumed as indicated by TLC analysis. After completion of the reaction, aqueous solution of $\mathrm{HCl}(1 \mathrm{~N})$ was added to the reaction mixture. The aquous phase was washed with $\mathrm{CH}_{2} \mathrm{Cl}_{2}$ and then aqueous ammonia was added to $\mathrm{pH} 7 \sim 8$. The precipitate formed was filtered and dried in vacuum $\left(60^{\circ} \mathrm{C}\right)$ to yield the catalyst $\mathbf{3}$ (recovery yield $=>95 \%$ ) as white solid. The combined organic phase was washed with saturated $\mathrm{NaHCO}_{3}$ solution, dried over anhydrous $\mathrm{Na}_{2} \mathrm{SO}_{4}$, and concentrated. Purification by column chromatography (EtOAc:Hexane = 1:4 - 1:10) gave the hemiester product. The enantiomeric excess (ee) was determined by the HPLC analysis of a diastereomeric mixture of the corresponding amide ester prepared from the hemiester according to the literature procedure. ${ }^{6,10}$

Acknowledgments. This work was supported by grants NRF-20090085824 (Basic Science Research Program, MEST), NRF-2010-0029698 (Priority Research Centers Program, MEST), R11-2005-008-00000-0 (SRC program, MEST), R312008-000-10029-0 (WCU program, MEST) and B551179-1003-00 (Cooperative R\&D Program, Korea Research Council Industrial Science and Technology).

\section{References}

1. For reviews on asymmetric alcoholysis of cyclic anhydrides, see: (a) Spivey, A. C.; Andrews, B. I. Angew. Chem. Int. Ed. 2001, 40, 3131-3134. (b) Chen, Y.-G.; McDaid, P.; Deng, L. Chem. Rev. 2003, 103, 2965-2984. (c) Atodiresei, I.; Schiffers, I.; Bolm, C.
Chem. Rev. 2007, 107, 5683-5712. (d) Johnson, J. B.; Rovis, T. Acc. Chem. Res. 2008, 41, 327-338. (e) Song, C. E.; Lee, J. W.; Jang, H. B.; Lee, J. E. Cinchona-Based Organocatalysts for Desymmetrization of meso-Compounds and (Dynamic) Kinetic Resolution of Racemic Compounds In Cinchona Alkaloids in Synthesis \& Catalysis; Song, C. E., Ed.: Wiley-VCH: Weinheim, 2009, Chap. 11, pp. 325-357.

2. For reviews on the stereoselective synthesis of $\gamma$-amino acids, (a) Trabocchi, A.; Menchi, G.; Guarna, A. Synthesis of $\gamma-$ and $\delta-$ Amino Acids In Amino Acids, Peptides and Proteins in Organic Chemistry; Hughes, A. B., Ed.; Wiley-VCH: Weinheim, 2009; Vol. 1, Chap. 13, pp 527-571. (b) Hanrahan, J. R.; Johnston, G. A. R. Synthesis of $\gamma$-aminobutyric Acid Analogs In Amino Acids, Peptides and Proteins in Organic Chemistry; Hughes, A. B., Ed.; Wiley-VCH: Weinheim, 2009, Vol. 1, Chap. 14, pp 573-689. (c) Ordóñez, M.; Cativiela, C. Tetrahedron: Asymmetry 2007, 18, 3-99.

3. (a) Liu, L. T.; Hong, P. C.; Huang, H. L.; Chen, S. F.; Wang, C. L. J.; Wen, Y. S. Tetrahedron: Asymmetry 2001, 12, 419-426. (b) Yu, M. S.; Lantos, I.; Peng, Z. Q.; Lu, J.; Cacchio, T. Tetrahedron Lett. 2000, 41, 5647-5651.

4. (a) Huang, X.; Zhu, J.; Broadbent, S. Tetrahedron Lett. 2010, 51, 1554-1557. (b) Huang, X.; Broadbent, S.; Dvorak, C.; Zhao, S.-H. Org. Proc. Res. Dev. 2010, 14, 612-616.

5. (a) Yamamoto, K.; Nishioka, T.; Oda, J. Tetrahedron Lett. 1988, 29, 1717-1720. (b) Ozegowski, R.; Kunath, A.; Schick, H. Tetrahedron: Asymmetry 1993, 4, 695-698. (c) Fryszkowska, A.; Frelek, J.; Ostaszewski, R. Tetrahedron 2005, 61, 6064-6072. (d) Fryszkowska, A.; Komar, M.; Koszelewski, D.; Ostaszewski, R. Tetrahedron: Asymmetry 2005, 16, 2475-2485. (e) Fryszkowska, A.; Komar, M.; Koszelewski, D.; Ostaszewski, R. Tetrahedron: Asymmetry 2006, 17, 961-966.

6. Rho, H. S.; Oh, S. H.; Lee, J. W.; Lee, J. Y.; Chin, J.; Song, C. E. Chem. Commun. 2008, 1208-1210.

7. Peschiulli, A.; Gun'ko, Y.; Connon, S. J. J. Org. Chem. 2008, 73, 2454-2457.

8. Lee, J. W.; Ryu, T. H.; Oh, J. S.; Bae, H. Y.; Jang, H. B.; Song, C. E., Chem. Commun. 2009, 7224-7226.

9. Jang, H. B.; Rho, H. S.; Oh, J. S.; Nam, E. H.; Park, S. E.; Bae, H. Y.; Song, C. E. Org. Biomol. Chem. 2010, 8, 3918-3922

10. (a) Oh, S. H.; Rho, H. S.; Lee, J. W.; Lee, J. E.; Youk, S. H.; Chin, J.; Song, C. E. Angew. Chem., Int. Ed. 2008, 47, 7872-7875. (b) Youk, S. H.; Oh, S. H.; Rho, H. S.; Lee, J. E.; Lee, J. W.; Song, C. E. Chem. Commun. 2009, 2220-2222. (c) Park, S. E.; Nam, E. H.; Jang, H. B.; Oh, J. S.; Some, S.; Lee, Y. S.; Song, C. E., Adv. Synth. Catal. 2010, 352, 2211-2217. 